International Journal of Engineering \& Technology, $7(4.4)(2018) 35-37$
International Journal of Engineering \& Technology
SPC
Website: www.sciencepubco.com/index.php/IJET
Research paper

\title{
Application of Anfis-Pid Controller for Statcom to Enhance Power Quality in Power System Connected Wind Energy System
}

\author{
Huu Vinh, Nguyen 1*; Hung, Nguyen2; Kim Hung, Le 3 \\ ${ }^{1}$ Hochiminh City Power Company, Vietnam \\ ${ }^{2}$ Hochiminh City University of Technology (HUTECH), Vietnam \\ ${ }^{3}$ Danang University of Technology, Vietnam \\ *Corresponding author E-mail:nguyenhuuvinhdlhcm@gmail.com,n.hung@hutech.edu.vn, lekimhung@dut.udn.vn
}

\begin{abstract}
In this paper, a proposed ANFIS-PID controller for the STATCOM to improve transient stability of the power system including DFIG based wind farm based on their nonlinear modeling is presented. The comparative simulation results in two cases of no controller and the ANFIS-PID controller for the STATCOM when occurs a three-phase short-circuit fault in the studied multi-machine power system are shown. It is shown the effectiveness of the proposed ANFIS-PID controller and applicability to a practical power system for enhancing power quality in transient time under large disturbance.
\end{abstract}

Keywords:Static synchronous compensator (STATCOM), Adaptive neuro-fuzzy inference system - proportional integral derivative (ANFIS-PID), Power Quality, Wind Energy

\section{Introduction}

At the present, wind energy has growth a lot in the world and become competitive with other renewable-energy power generation options such as solar energy, tidal, marine, and so on. Many large scale offshore wind farms have been installed and commercially operating [3]. But when operating, power fluctuations will adverse impact to the power quality of the power systems connected to offshore wind farms, special in case of supplying amount of large electric power to the grids. For solving this problem, STATCOM is selected as the most suitable device that can be used not only to control the voltage at the connected bus but also to improve the power system transient stability. In [4], STATCOM is used to contribute to improve transient stability and low-voltage ridethrough capability of wind farms. In [5], a STATCOM was applied to connect at the bus of weak grid to maintain stable voltage of the bus by protecting wind farm. In [6], a STATCOM is installed in system to supply a reactive power for large loads that could cause serious effects on grid stability. For DFIG wind turbine, a back to back converter for high-power applications in the rotor circuit is used for guarantee control responses of system [7]. By connecting the stator windings directly to the network, a DFIG wind turbine is extremely sensitive to grid disturbances such as a short-circuit fault. To reduce fluctuations of power of a DFIGbased wind farm fed to a power grid with disturbances, a variable frequency transformer is applied for improvement of the dynamic performance of DFIG-based wind farm in multi-machine systems [8].

In the previous time, many research results used PID controller for STATCOM. However, in power system connected to wind energy system, there are many elements and have complex configurations and nonlinear dynamic modeling, and conventional PID controller are not robust for system stability control. In [9], fuzzy logic controller has been used to enhance the power stability in interconnected power system including two-area, four-generator. In another research, in [10], a cooperating PI and FL controller to enhance dynamic and steady state performance of a speed controller of permanent magnet synchronous motor are presented. For solving the remain problems, the tuning PID controller is effectively used when the operating condition is changed for improvement of dynamic and steady state performance [11]. The neuro-adaptive learning techniques supply a procedure for the fuzzy modeling procedure to acquire information about a data set. The technique gives the fuzzy logic capability to compute the membership function parameters that allow the associated fuzzy inference system to track the given input and output data for controlling D-Statcom [12].

This paper proposes a ANFIS-PID controller for the STATCOM to improve transient stability of the power system connected to DFIG based wind farm based on their nonlinear modeling. The paper has five sections. The first section is introduction. The second section is modeling of the studied power system. In third section, the ANFIS-PID controller for STATCOM is designed. Transient responses of the studied system with and without the designed controller are shown in section fourth. Finally, the conclusions of the paper are presented in the last section.. 


\section{Configuration of the Studied Power System}

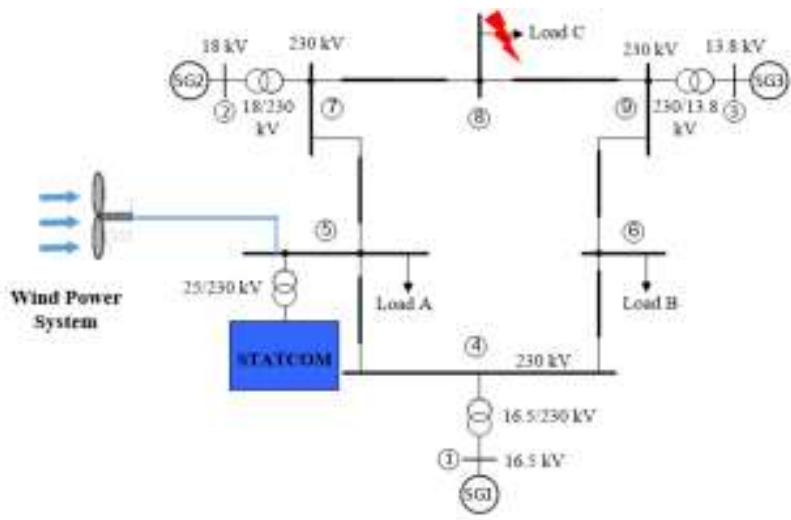

Figure 1:. Configuration of the studied power system

The configuration of the studied power system is shown in Figure 1. It including three Synchronous Generators (SG1, SG2, SG3) supply power to three loads (Load A, Load B, Load C) at bus 5, 6 and 8 ; the STATCOM of $\pm 20 \mathrm{MVAr}$ is connected to bus 5 were also connected the DFIG based on wind power system (WPS) called a point of common coupling (PCC). The mathematical modeling of the main components are described as below.

\subsection{Modeling of STATCOM}

In this part, the mathematical model of Statcom is presented. In the modeling, the output voltage is divided into two components represented in $\mathrm{d}$ and $\mathrm{q}$ axes as following $[12,14]$ :

$v_{d s t a}=V_{d c s t a} \cdot k m_{s t a} \cdot \sin \left(\theta_{\text {bus }}+\alpha_{s t a}\right)$

$\mathrm{v}_{\mathrm{qsta}}=\mathrm{V}_{\mathrm{dcsta}} \cdot \mathrm{km}_{\mathrm{sta}} \cdot \cos \left(\theta_{\text {bus }}+\alpha_{\text {sta }}\right)$

$\left(C_{m}\right) p\left(V_{d c s t a}\right)=\omega_{b}\left[I_{d c s t a}-\left(V_{d c s t a} / R_{m}\right)\right]$

where $v_{d s t a}$ and $v_{\text {qsta }}$ are the voltages of $\mathrm{d}$ and $\mathrm{q}$ axes at the output terminals of the STATCOM, respectively; $k m_{s t a}, \alpha_{s t a}$ are themodulation index and phase angleof the STATCOM, respectively; $\theta_{\text {bus }}$ is the voltage phase angle of the common $\mathrm{AC}$ bus; $V_{d c s t a}$ is the DCvoltageofthe DC capacitor $C_{m} ; I_{d c s t a}$ is the pu DC current flowing into the positive terminal of $V_{d c s t a} ; R_{m}$ is the pu equivalent resistance of the STATCOM; $i_{q s t a}$ and $i_{d s t a}$ are the currents in q and $\mathrm{d}$ axes flowing into the terminals of the STATCOM, respectively.

In Figure 2,the DC voltage $V_{d c s t a}$ is controlled by the phase angle $\alpha_{\text {sta }}$ while the voltage $v_{s t a}$ is varied by changing the modulation index $\mathrm{km}_{\text {sta }}$.

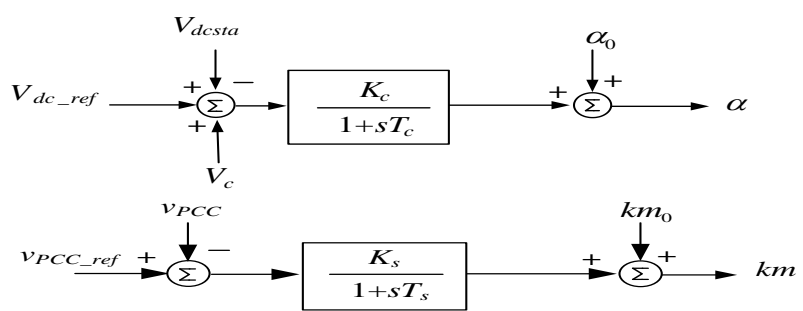

Figure 2. Control scheme of STATCOM

\subsection{Modeling of DFIG Wind Turbine}

Figure 3 shows the control block of a DFIG wind turbine. The DFIG is driven by wind turbine through a gearbox. The pitch angle of wind turbine is also controlled. The DFIG stator windings are connected to the low voltage side of the step-up transformer supply power to AC bus, while the DFIG rotor windings are also connected to another low-voltage side of the step-up transformer through an AC-DC-AC converter, a step-up transformer, and a control system.

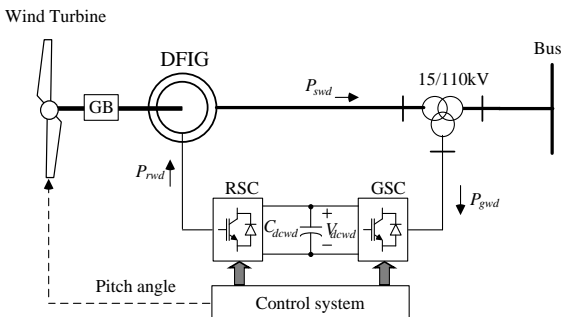

Figure 3.: One-line diagram of wind DFIG

In this paper, a DFIG modeling is developed under a dq-axis synchronous reference frame. The modeling of the system are presented in [7-11]

\section{ANFIS Controller Design}

The Figure 4 shows the structure of designed ANFIS. In the model, a circle symbol is a fixed node, whereas a square symbol is an adaptive node. The studied system has two inputs $\mathrm{x}, \mathrm{y}$ and single output $\mathrm{f}$, and a fuzzy rule set can be shown as follow [2]:

if $x$ is $G_{i}$ and $y$ is $H_{i}$ then $f i=u_{i} x+v_{i} y+r_{i}$. where $G_{i}$ and $H_{i}$ are fuzzy sets in the antecedent and $z=f(x, y)$ is a crisp function in the consequent; $u_{i}, v_{i}, r_{i}$ are the adjusting parameters of the rule.

In the study, each designed ANFIS model consists of five layers are presented as follow [2]:

Layer 1: The layer is used for input fuzzification. The mathematical modeling of the layer can be shown as follow:

$$
O_{i j}^{(1)}=\mu_{j}\left(I_{i j}^{(1)}\right) ; \quad \mu_{j}\left(x_{i}\right)=\frac{1}{1+\left.\left|\frac{x_{i}-c_{i j}}{a_{i j}}\right|\right|^{b_{i j}}}
$$

where, $\left(a_{i j}, b_{i j}, c_{i j}\right)$ are the parameters set referred to as parameters of premise.

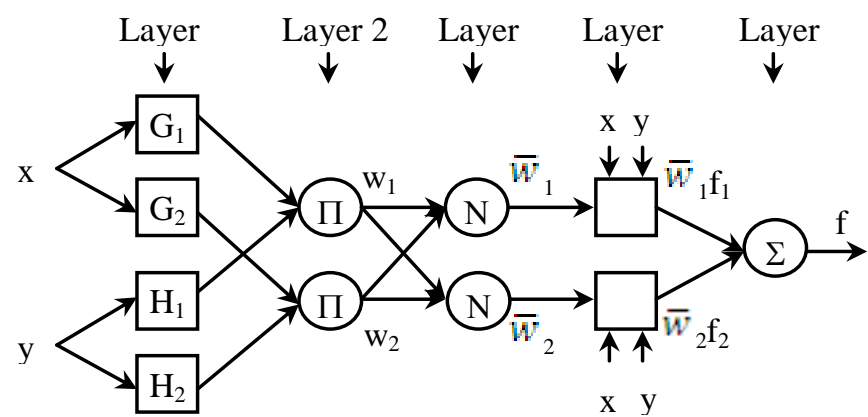

Figure 4: . Configuration of ANFIS

Layer 2: In this layer, the total number of rules is 25 . Each output of node shows the rule activation level as the following:

$O_{k}^{(2)}=w_{k}=\prod_{i=1}^{q} O_{i j}^{(1)}$

Layer 3: The output of the k-th node is the firing strength of each rule divided by the total sum of the activation values of all the fuzzy rules. 


$$
O_{k}^{(3)}=\overline{w_{k}}=\frac{O_{k}^{(2)}}{\sum_{m=1}^{y^{2}} O_{m}^{(2)}}
$$

Layer 4: Each node $k$ in the layer is attended by a set of regulating parameters namely as $d_{1 k}, d_{2 k}, \ldots, d_{N k}, d_{y k}, d_{0}$, and calculates implements the linear function as follows:

$$
O_{k}^{(4)}=\overline{w_{k}} f_{k}=\overline{w_{k}}\left(d_{1 k} I_{1}^{(1)}+d_{2 k} I_{2}^{(1)}+\ldots+d_{y k} I_{y}^{(1)}+d_{0}\right)
$$

Layer 5: The last layer has only single node that computes the total output as the summation of all incoming signals of the node, which is shown as following:

$$
O^{(5)}=\sum_{k=1}^{y^{2}} O_{k}^{(4)}=\sum_{k=1}^{y^{2}} \overline{w_{k}} f_{k}=\frac{\sum_{k=1}^{y^{2}} w_{k} f_{k}}{\sum_{k=1}^{y^{2}}}
$$

The main task of the learning algorithm for the structure of ANFIS is to tune all the adjustable parameters to make the output of the system match the training data. The training algorithm needs a set defined between input and output signals.

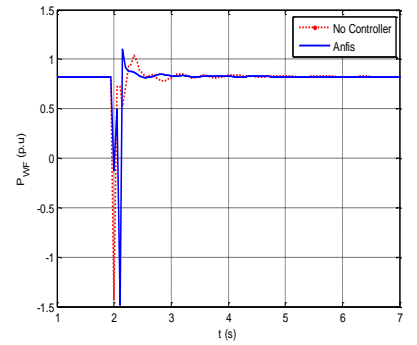

a. Active power of DFIG

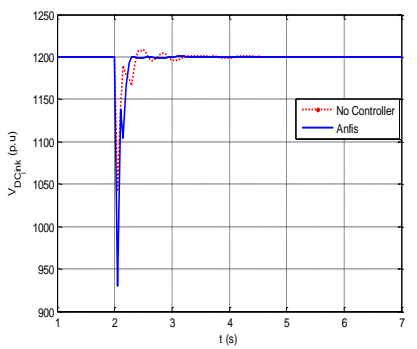

c. DC link Voltage of DFIG

Figure 5:.Transient responses of DFIG under three-phase fault

\section{Simulation Results}

In this section, nonlinear system model is used for simulation to compare the oscillation damping characteristics contributed by the proposed STATCOM using the ANFIS-PID controller on transient stability improvement of the studied power system under a threephase short-circuit fault at the bus 5. It is assumed that the DFIG based wind farm operates under a base wind speed of 12 meter/second.

To verify the effectiveness of the designed ANFIS-PID controller, simulation results for the above system are performed in Matlab/Simulink software. Figure 5 shows the transient responses of DFIG in the studied system that installed Statcom for two case of without (dot red lines) and with the ANFIS-PID controller (solid blue lines) when a three-phase short-circuit fault occurs at $t=1$ second and is cleared after maintaining 100ms. In Figure 5 from (a) to (d), they show the active power, rotor speed, DC link voltage of DFIG and voltage at PCC, respectively. From the above simulation results, it show that the transient responses of DFIG in the studied system have better oscillation damping performance when a STATCOM is in service since the system quickly approaching their steady state stability values with smaller oscillations.

\section{Conclusion}

This paper proposes an ANFIS-PID controller for the STATCOM to improve transient stability of the power system including DFIG based wind farm based on their nonlinear modeling. The simulation results in two cases of no controller and the ANFIS-PID controller for the STATCOM when occurs a three-phase short-circuit fault in the studied multi-machine power system are shown for comparison. It is shown the effectiveness of the proposed ANFISPID controller and applicability to a practical power system.

\section{References}

[1] P. M. Anderson and A. A. Fouad, "Power System Control and Stability", IEEE Press, 2d ed., 2003.

[2] J. Jang, C. Sun, and E. Mizutani, "Neuro-Fuzzy and Soft Computing”, Prentice Hall, Upper Saddle River, NJ, USA, 1997.

[3] M.P. Palsson, T. Toftevaag, K. Uhlen, and J.O.G Tande, "Largescale wind power integration and voltage stability limits in regional networks," in Proc. Power Engineering Society Summer Meeting, 2002 IEEE, vol. 2, no., pp.762,769, 25-25 July 2002.

[4] B. Pokharel and W. Gao, "Mitigation of disturbances in DFIGbased wind farm connected to weak distribution system using STATCOM," in Proc. North American Power Symposium (NAPS), Arlington, Texas, USA, Sep. 26-28, 2010, pp. 1-7.

[5] J. G. Slootweg, H. Polinder, and W. L. Kling, "Dynamic modeling of a wind turbine with doubly fed induction generator," in Proc. IEEE PES Summer Meeting, Vancouver, Canada, vol. 1, Jul. 15-19, 2001.

[6] M. N. Eskander and S. I. Amer, "Mitigation of voltage dips and swells in grid-connected wind energy conversion systems," in Proc. ICCAS-SICE, Fukuoka, Japan, Aug. 2009, pp. 885-890.

[7] J. Zhai and H. Liu, "Reactive power control strategy of DFIG wind farms for regulating voltage of power grid," in Proc. IEEE PES General Meeting | Conference \& Exposition, pp.1,5, 27-31 July 2014.

[8] L. Wang and L.-Y. Chen, "Reduction of power fluctuations of a large-scale grid-connected offshore wind farm using a variable frequency transformer." IEEE Trans. on Sustainable Energy, vol. 2, no. 3, pp. 226-234, Apr. 2011.

[9] O K. E., M S. M., Takahashi R., and Tamura J., Improvement of fault ride through capability of wind farms using DFIG considering $S D B R$, in Proc. 14th European Conference on Power Electronics and Applications, 2011.

[10] J. Chhor, P. Tourou and C. Sourkounis, "Evaluation of state-based controlled STATCOM for DFIG-based WECS during voltage sags", 2016 IEEE ICRERA, Birmingham, 2016, pp. 463-471

[11] M. N. Uddin and R. S. Rebeiro, "Improved dynamic and steady state performance of a hybrid speed controller based IPMSM drive", in Proc. IEEE Industry Applications Society Annual Meeting (IAS), pp.1-8, 9-13 Oct. 2011

[12] A. Varshney and R. Garg, "Comparison of different topologies of fuzzy logic controller to control D-STATCOM", 2016 3rd International Conference on Computing for Sustainable Global Development (INDIACom), New Delhi, 2016, pp. 2492-2497.

[13] D. Shen, and P. W. Lehn, "Modeling, analysis and control of a current source inverter based STATCOM", IEEE Trans. on Power Delivery. Vol.17. No. 1, pp. 248-253, 2002.

[14] A. Jain, K. Joshi, A. Behal, and N. Mohan, "Voltage regulation with STATCOMs: Modeling, control and results", IEEE Trans. Power Delivery, vol. 21, no. 2, pp. 726-735, 2006. 